Original Article

\title{
THE EFFECT OF THERMAL STERILIZATION AND EXCIPIENTS ON THE STABILITY OF ASCORBIC ACID IN AQUEOUS SOLUTIONS
}

\author{
A. V. SYROESHKIN ${ }^{1}$, T. V. PLETENEVA ${ }^{1 *}$, E. V. USPENSKAYA ${ }^{1}$, O. V. LEVITSKAYA ${ }^{1}$, S. S. BARSEGYAN ${ }^{2}$, I. A. \\ ZLATSKY ${ }^{1}$, M. A. TRIBOT-LASPIERE ${ }^{1}$
}

${ }^{1}$ Peoples Friendship University of Russia (RUDN University), 6 Miklukho-Maklaya St, Moscow, 117198, Russian Federation, ${ }^{2}$ Russian Center for Forensic Medicine, 12/13 Polikarpova St, Moscow, 125284, Russian Federation

Email: tvplet@mail.ru

Received: 10 May 2019, Revised and Accepted: 06 Aug 2019

\begin{abstract}
Objective: To investigate the thermal stability of aqueous solutions of L-ascorbic acid (AA) and its reactions with excipients for the improvement of the injection forms technology.

Methods: Solutions of L-ascorbic acid were prepared using deuterium depleted water (DDW-«light» water, $\mathrm{D} / \mathrm{H}=4 \mathrm{ppm}$ ) and natural deionized high-ohmic water (BD, D/H=140 ppm). The optical rotation was observed using an automatic polarimeter Atago POL-1/2. Electrospray tandem mass spectra were recorded by Sciex X500R QTOF. Electronic spectra were recorded by UV-spectrometer Cary 60 (Agilent). Unicellular biosensor (Spirotox-test) was used for investigation of excipients influence on the AA biological activity. The statistical analysis was carried out using the OriginPro®9 packages.
\end{abstract}

Results: The results demonstrate the thermal instability of AA. The optical activity of injection forms of AA differs from model solutions with the same concentration and $\mathrm{pH}$ value but without heat treatment. Monitoring of solutions by the LC-ESI-MS/MS method made it possible to characterize the nature of some thermal decomposition products. Thermodynamic calculations and evaluation of biological activity (Spirotox-test) indicate that AA interacts with sulfite-ion by redox mechanisms. Excipients in AA aqueous solutions decrease, but DDW increases the biological object lifetime.

Conclusion: The use of the set of physicochemical and biological methods to study the effect of heat treatment of L-ascorbic acid solutions in the presence of sulfur (IV) compounds as excipients made it possible to identify decomposition products of the active pharmaceutical ingredient. The results indicate the need to exclude sterilization of the AA injection form by the thermal method and replace it with an alternative one, for example, with gamma radiation treatment.

Keywords: L-Ascorbic acid, Heat sterilization, Sulfur (IV) excipients, Polarimetry, Electron spectrometry, Electrospray tandem mass spectrometry, Spirotox-test

(C) 2019 The Authors. Published by Innovare Academic Sciences Pvt Ltd. This is an open-access article under the CC BY license (http://creativecommons.org/licenses/by/4.0/) DOI: http://dx.doi.org/10.22159/ijap.2019v11i5.34025

\section{INTRODUCTION}

Since the middle of the last century, the stability of ascorbic acid (AA), which has antioxidant properties in mammals and in foodstuffs, has been actively studied [1-9]. AA degradation can occur spontaneously, even in an anaerobic environment, and under the influence of a number of factors $[1,2,5]$. An increase in temperature and in alkalinity of its solution, exposure to radiation, the presence of $d$-elements ions and compounds with a more positive redox potential are the main causes of AA degradation.

To increase the stability of AA, sodium sulfite $\left(\mathrm{Na}_{2} \mathrm{SO}_{3}\right)$ or its analogues with sulfur (IV) in anionic form - sodium hydrogen sulfite/bisulfite $\left(\mathrm{NaHSO}_{3}\right)$ or sodium metabisulfite/pyrosulfite $\left(\mathrm{Na}_{2} \mathrm{~S}_{2} \mathrm{O}_{5}\right)-$ are added to liquid dosage forms. At the same time, the possibility of AA interaction with these excipients, which exhibit oxidative properties with respect to vitamin C, is ignored $[10,11]$. Redox reactions are accompanied by an increase in impurities in the liquid dosage form. The nature of these compounds can vary depending on the acidity of the medium. The approximation to the $\mathrm{pH}$ of biological media increases the instability of AA and, therefore, the number of products of interaction with excipients.

In accordance with the technological regulations, sterilization of AA injection forms is performed at $100{ }^{\circ} \mathrm{C}(15 \mathrm{~min})$ or $120^{\circ} \mathrm{C}(8 \mathrm{~min})$ [12-14], although the recommended temperature range for storing the finished injection form is between $2{ }^{\circ} \mathrm{C}$ to $8{ }^{\circ} \mathrm{C}[15,16]$. To justify the inadmissibility of thermal sterilization of injectable forms of AA, it is possible to use the polarimetry method: the optical activity of injectable forms of AA should differ from model solutions with the same $\mathrm{pH}$ and concentration values but without heating. Additional monitoring of model solutions by LC-ESI-MS/MS can characterize the nature of the products of thermal decomposition of AA.
Thermodynamic calculations, polarimetric measurements and evaluation of biological activity (Spirotox test) can demonstrate that AA and sulfite ion interact through redox mechanisms.

The introduction of sulfur (IV) compounds as reducing agents in the AA injection forms and their subsequent thermal sterilization should be excluded since they are accompanied by contamination of the pharmaceutical product.

The investigation of the thermal stability of ascorbic acid in aqueous solutions and its reactions with excipients will help to improve the technology for producing injection forms.

\section{MATERIALS AND METHODS}

\section{Materials}

L-threo-Ascorbic acid was obtained from Sigma-Aldrich (the content of API $\geq 99 \%$ ). Deionized high-ionic water (specific electrical resistivity of $18.2 \mathrm{M} \Omega \times \mathrm{cm}$ at $25^{\circ} \mathrm{C}$ ) was prepared by purifying a pyrogenic distilled water $(\mathrm{BD}, \mathrm{D} / \mathrm{H}=140 \mathrm{ppm}$ ) on a Milli-Q system (Millipore, Great Britain). Water with low deuterium content (deuterium depleted waterDDW, D/H = 4 ppm, "light" water) was obtained by low-temperature vacuum distillation. Methanol HPLC grade, acetonitrile (Merck, hyper grade for LC-MS), ammonium formate (for HPLC, $\geq 99.0 \%$, Fluka Sigma Aldrich), deionized water for HPLC were used in experiment.

The injectable forms of vitamin of different manufacturers contained: $5.000 \mathrm{~g} \mathrm{AA}, 0.200 \mathrm{~g} \mathrm{Na}_{2} \mathrm{SO}_{3}, 2.385 \mathrm{~g} \mathrm{NaHCO}_{3}$, distilled water to $100 \mathrm{ml}$ ( $\mathrm{pH}$ 6.3). Model solutions ( $5 \% \mathrm{AA}$ ) were prepared by dissolving $5 \mathrm{~g} \mathrm{AA}$ in $100 \mathrm{ml}$ of BD or DDW and adding excipients at pH 6.3 .

\section{Methods}

The optical activity was determined using the Atago POL-1/2 polarimeter (Japan), in the $100 \mathrm{~mm}$ cell, the measurement accuracy 
of $\pm 0.002^{\circ}$ and the resolution of $0.0001^{\circ}$. The electronic Peltier module was used for setting the required temperature $\left(T=20^{\circ} \mathrm{C}\right)$. UV spectra were recorded using an Agilent Cary 60 Spectrometer.

Liquid chromatography-electrospray ionization-tandem mass spectrometry (LC-ESI-MS/MS) was used for monitoring AA degradation. Chromatographic separation of the mixture of compounds was carried out under the following conditions: in a gradient mode (Kinetex column $\mathrm{C} 18$ from Phenomenex); the eluent flow rate $0.4 \mathrm{ml} / \mathrm{min}$; the column temperature $40^{\circ} \mathrm{C}$; the volume of injected sample $10 \mu \mathrm{L}$. The mobile phase consisted of solution A $(0.01$ $\mathrm{M}$ solution of ammonium formate) and solution B (methanolacetonitrile 50:50). High-resolution mass spectra were obtained using Sciex X500R Q-TOF mass spectrometer with a Turbo $\mathrm{V}^{\mathrm{m}}$ ionization source. The mass spectrometer was operated in the negative electrospray ionization (ESI) mode. High-resolution mass spectra were obtained in the mass range 10-1000 Da. Mass fragmentation was carried out in collision energy (CE) of $35 \mathrm{~V}$ and collision energy spread (CES) in the interval $\pm 15 \mathrm{~V}$. The voltage of the ionization source was $2500 \mathrm{~V}$ at $600^{\circ} \mathrm{C}$. Unicellular biosensor based on free-living ciliate Spirostomum ambiguum (the class Heterotrichea)-Spirotox-test.

\section{Statistics}

The findings were processed by the statistical methods using software packages of Origin Pro 9.1. Each value on the fig. represents «mean \pm SD», *P<0.05.

\section{RESULTS AND DISCUSSION}

The AA degradation kinetics was investigated at $90{ }^{\circ} \mathrm{C}$ and $\mathrm{pH} 6.3$ (phosphate buffer solution). In 45, 90, 135 and 180 min after the heating start the optical rotation angle and the absorption maximum at $\lambda=256$ $\mathrm{nm}$ of 5 solutions, including the original, were detected at $20^{\circ} \mathrm{C}$ (fig. 1).

As can be seen from the obtained results, the thermal degradation of AA does not follow the steady-state kinetics mechanism, and each experimental point is characterized by a significant amount of relative standard deviation. In the time interval 50-100 min, an absorption increase is observed. This is the result of the intermediate degradation product formation that absorbs light at $265 \mathrm{~nm}$. With longer heating, the absorption of the solutions decreases as a result of the degradation of both AA and intermediate decomposition products.
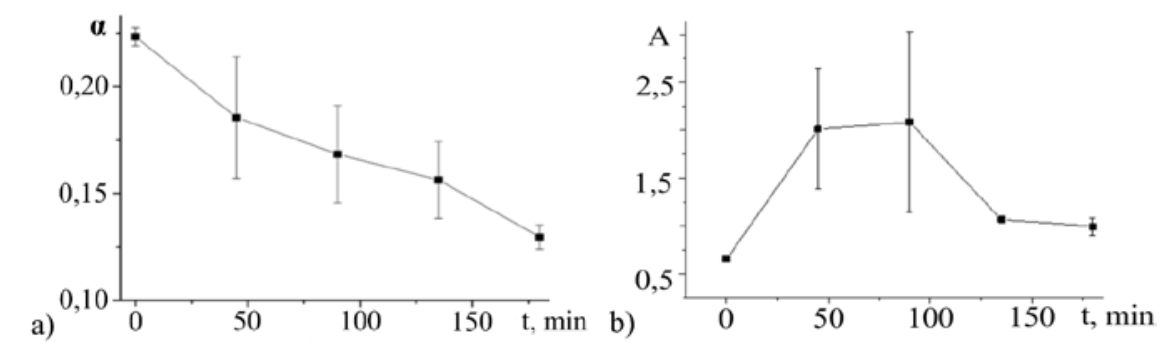

Fig. 1: Kinetics of L-ascorbic acid degradation at $90^{\circ} \mathrm{C}$ : a) the values of the angle of the polarized light plane rotation $(\alpha), \mathrm{C}=0.2 \%, \mathrm{~T}=20$ ${ }^{\circ} \mathrm{C}$. b) Absorption at $265 \mathrm{~nm}(\mathrm{~A}), \mathrm{C}=0.002 \% . \mathrm{n}=5, \mathrm{P}=0.95$

Chromatographic analysis of solutions with different thermal exposure periods indicates a decrease in the peaks of AA and dehydroascorbic acid (DGAA) in $45 \mathrm{~min}$ after the heating start (fig. 2). After 90 min there are many chromatographic peaks corresponding to the decay products. After 180 min of dissolution, they were not detected in either ascorbic or dehydroascorbic acids.
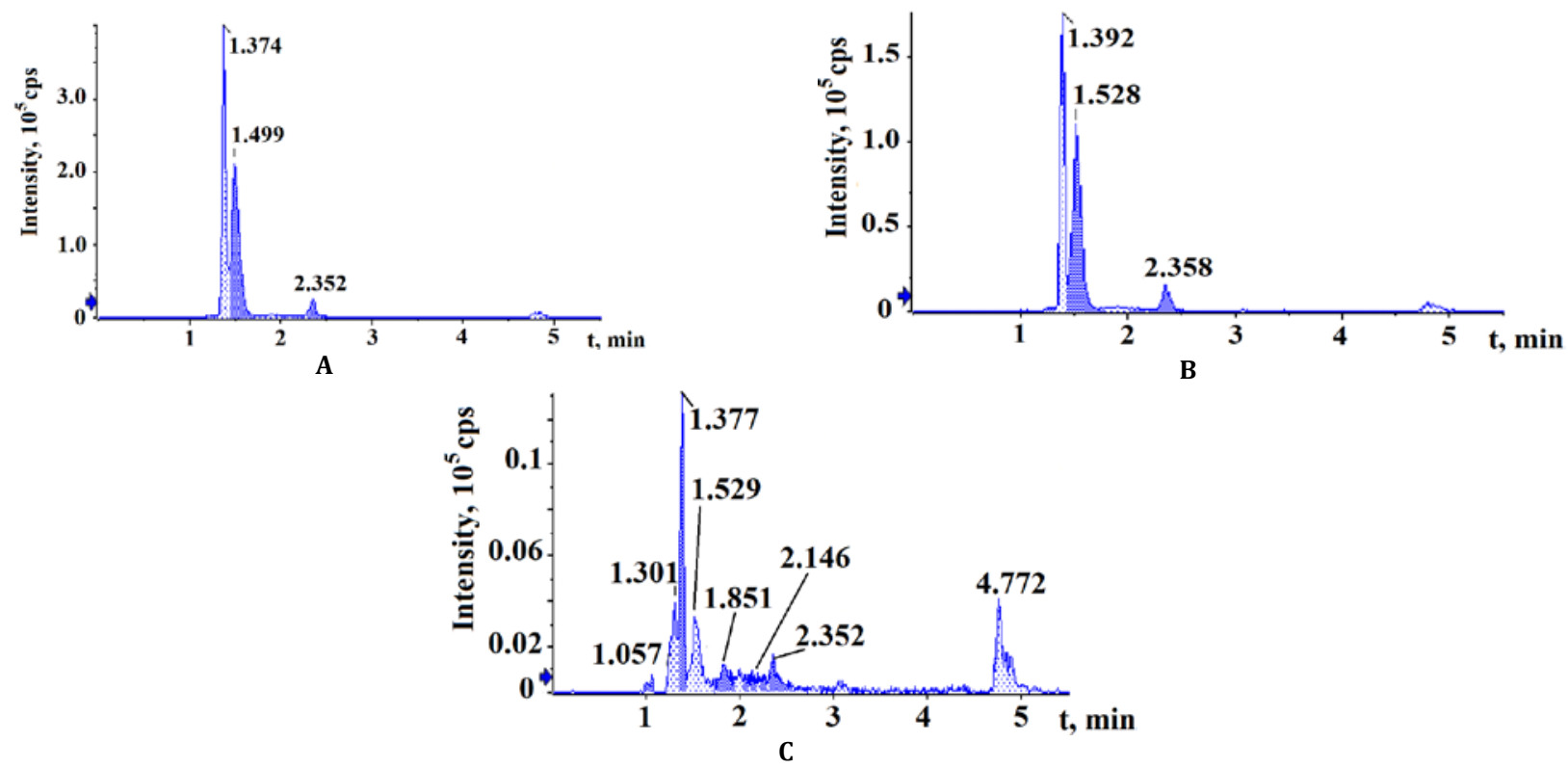

Fig. 2: HPLC chromatograms of ascorbic acid solution (pH=6,6) heated at $90^{\circ} \mathrm{C}$ for 0 (a), 45 (b), 90 (c) $\min$

Some of the degradation products were identified by liquid chromatography-electrospray ionization-tandem mass spectrometry (Fig.3). Among the identified compounds there are derivatives with m/Z: 55-2-propyn-1-ol; 59-(E)-1,2-ethenediol or acetic acid; 71-3- hydroxypropen-1-al; 89-(1Z)-1-propene-1,2,3-triol or 2,3dihydroxypropanal; 99-1-keto-buta-1,3-diene-2,4-diol 143-5(hydroxymethyl)-2,3,4(5H)-furantrione; 173-dehydroascorbic acid or 5-(1,2-dihydroxyethyl)-2,3,4(5H)-furantrion. 
The results demonstrate the thermal instability of $\mathrm{AA}$, and the formation of numerous decomposition products does not obey the laws of stationary kinetics. That's why FDA believes that AA solutions after heat treatment are not safe; therefore low doses of gamma radiation should be used to sterilize injectable forms of vitamins, including ascorbic acid [16-18].

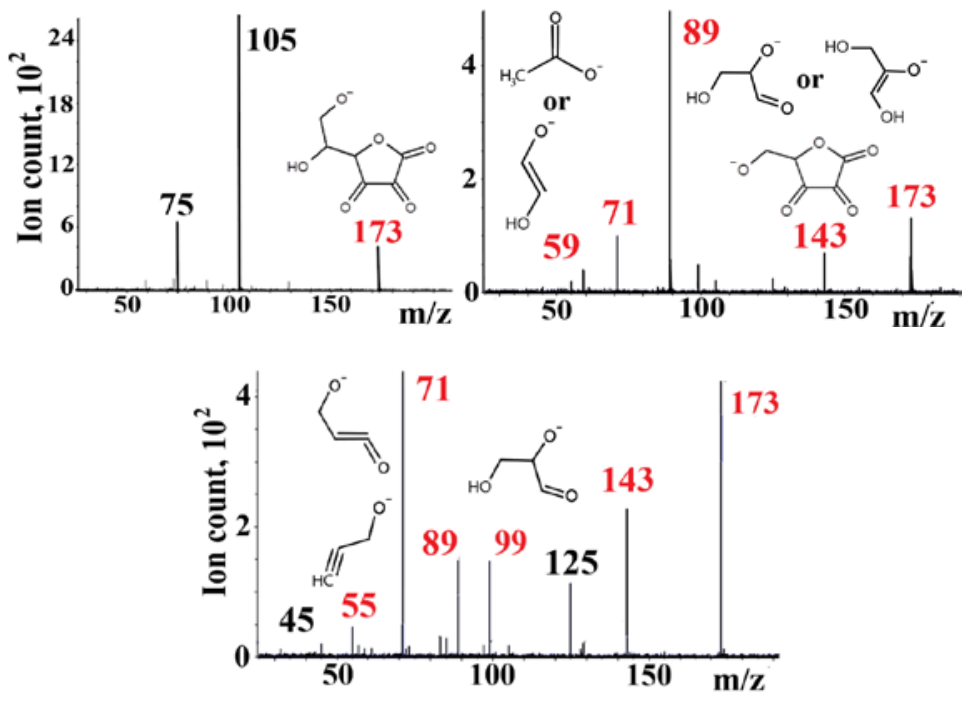

Fig. 3: Some derivatives of ascorbic acid in its solution heated at $90^{\circ} \mathrm{C}$ for $135 \mathrm{~min}$ by LC-ESI-MS/MS. Identified compounds are marked in red

The presence of $\mathrm{Na}_{2} \mathrm{SO}_{3}$ in the injection form exacerbates the situation, since when heated, in addition to the hydrolysis products and $\mathrm{pH}$ increasing, the redox interaction between the $\mathrm{SO}_{3}{ }^{2}$-ions and $\mathrm{AA}$ is possible. In these reactions, sodium sulfite loses its function as an excipient and plays the role of an oxidizing agent rather than a reducing agent with respect to AA. This can be demonstrated by the example of one of the possible reactions:

$$
\text { AA and DHAA }
$$

\section{AA and DHAA}

Electromotive force (EMF) of this process $\Delta \mathrm{E}^{\circ}=\mathrm{E}^{\circ}(\mathrm{Ox})-\mathrm{E}^{\circ}(\mathrm{Red})=\mathrm{E}$ ${ }^{\circ}\left(\mathrm{SO}_{3}{ }^{2-} / \mathrm{S}_{2} \mathrm{O}_{3}{ }^{2-}\right)-\mathrm{E}^{\circ}(\mathrm{DHAA} / \mathrm{AA})=0.608 \mathrm{~V}$, and Gibbs energ $\otimes \mathrm{G}{ }^{\circ}=-$

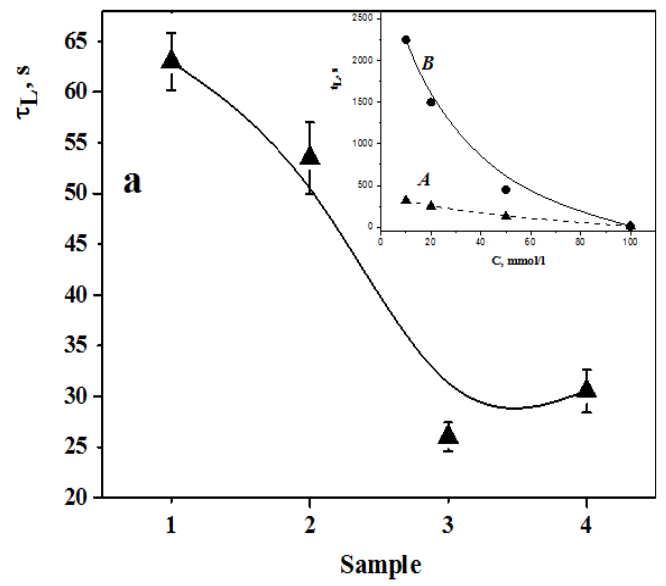

$\mathrm{n} \bullet \mathrm{F} \bullet \Delta \mathrm{E}^{\circ}=-234.7 \mathrm{~kJ} / \mathrm{mol}$. This value is many times greater than the values of the Gibbs energy for the state of chemical equilibrium $( \pm 10$ $\mathrm{kJ} / \mathrm{mol}$ ) [19]. Thus, on the basis of thermodynamic calculations, the possibility of the interaction of $\mathrm{AA}$ as a reducing agent with compounds of sulfur in an intermediate oxidation state $(+4)$ can be demonstrated.

The effect of disodium sulfite on the biological activity of AA was demonstrated on the Spirostomum ambigua biosensor (fig. 4). The $\mathrm{D} / \mathrm{H}$ ratio decrease in water leads to an increase in the lifetime of the ciliate due to the manifestation of the kinetic isotope effect [20-22] But any complication of the system due to the addition of excipients to the aqueous solution leads to a decrease in lifetime leads of the biological object. At the same time, there is also a noticeable increase in the specific optical rotation, which reflects a change in the chiral properties of the API solution $[1,2]$.

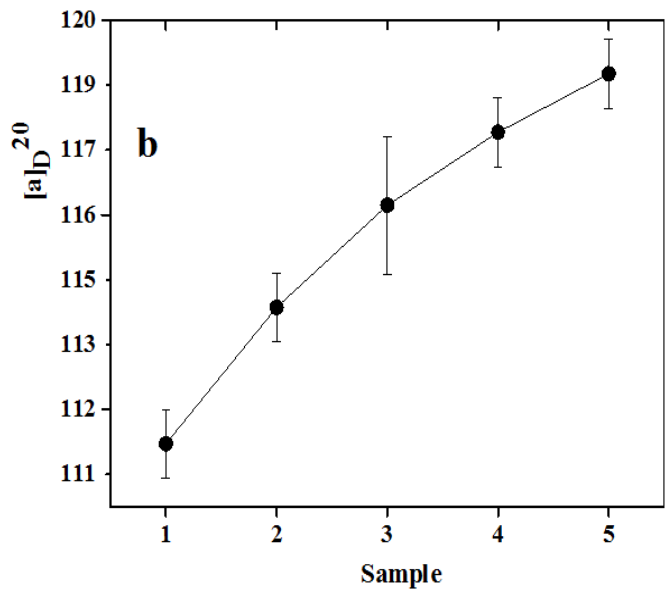

Fig. 4: The lifetime of the bilogical sensor (a) and specific rotation value (b) for laboratory model samples with different composition (1-4) and industrial injection form (5): 1-ascorbic acid (5 \%); 2 -ascorbic acid+NaHCO 3 ; 3 -ascorbic acid $+\mathrm{Na}_{2} \mathrm{SO}_{3} ; 4$-ascorbic acid $+\mathrm{Na}_{2} \mathrm{SO}_{3}+\mathrm{NaHCO}_{3} ;(\mathrm{pH}=6,30, \mathrm{n}=3, \mathrm{P}=0,95)$. The inset shows a plot of Spirostomum ambigua lifetime in $\mathrm{Na}_{2} \mathrm{SO}_{3}$ solutions with different ratios of $\mathrm{D} / \mathrm{H}$ in water: $A \mathbf{- 1 4 0} \mathrm{ppm} ; B-4 \mathrm{ppm}(\mathrm{n}=5, \mathrm{P}=0,95)$

The search for methods to protect AA drugs from degradation is not an easy task $[15,18,21,22]$ and requires an approach using a complex of analytical and biological methods $[1,6-9,20,23,24]$. This is especially important for injectable forms of AA [25]. The article results indicate that heating solutions of ascorbic acid and the use of sulfur compounds in the oxidation state +4 as excipients are 
accompanied by changes in their physical properties and chemical composition. This should be taken into account in the pharmaceutical production of injectable forms of AA and also in food production.

\section{CONCLUSION}

The use of the set of physicochemical and biological methods to study the effect of heat treatment of L-ascorbic acid solutions in the presence of sulfur (IV) compounds as excipients made it possible to identify decomposition products of the active pharmaceutical ingredient. The results indicate the need to exclude sterilization of the AA injection form by the thermal method and replace it with an alternative one, for example, with gamma radiation treatment.

\section{ACKNOWLEDGMENT}

The publication has been prepared with the support of the «RUDN University Program 5-100».

\section{AUTHORS CONTRIBUTIONS}

All the authors have contributed equally

\section{CONFLICT OF INTERESTS}

\section{Declared none}

\section{REFERENCES}

1. Syroeshkin AV, Pleteneva TV, Uspenskaya EV, Levitskaya OV, Tribot Laspiere MA, Zlatsky IA, et al. Polarimetric research of pharmaceutical substances in aqueous solutions with different water isotopologues ratio. Int J Appl Pharm 2018;10:243-8.

2. Mauludin R, Mohamad SFB, Suciati T. Formulation and characterization of ascorbyl palmitate loaded $\mathrm{o} / \mathrm{w}$ microemulsion. Int J Pharm Pharm Sci 2014;6:294-8.

3. Davies MB, Austin J, Partridge DA. Vitamin C. Its chemistry and biochemistry. Cambridge: The Royal Society of Chemistry; 1991.

4. Zia R, Nazir A, Khan MKI, Maan AA, Rashida. Preparation of ascorbic acid and cholecalciferol microsponges for topical application. Int J Pharm Pharm Sci 2017;9:280-7.

5. Bradshaw MP, Barril C, Clark AC, Prenzler PD, Scollary GR. Ascorbic acid: a review of its chemistry and reactivity in relation to a wine environment. Crit Rev Food Sci Nutr 2011;51:479-98.

6. Szultka M, Buszewska Forajta M, Kaliszan R, Buszewski B. Determination of ascorbic acid and its degradation products by high-performance liquid chromatography-triple quadrupole mass spectrometry. Electrophoresis 2014;35:585-92.

7. Dabbagh HA, Fatemeh Azami F. Experimental and theoretical study of racemization, stability and tautomerism of vitamin C stereoisomers. Food Chem 2014;164:355-62.

8. Gomez RB, Roux S, Courtois F, Bonazzi C. Spectrophotometric method for fast quantification of ascorbic acid and dehydroascorbic acid in the simple matrix for kinetics measurements. Food Chem 2016;211:583-9.

9. Allen F, Greiner R, Wishart D. Competitive fragmentation modeling of ESI-MS/MS spectra for putative metabolite identification. Metabolomics 2015;11:98-110.
10. Levitskaya OV, Syroeshkin AV, Pleteneva TV. Arrhenius kinetics as a bioactivity assessment criterion for drug substances and excipients. Pharm Chem J 2016;49:779-81.

11. Titorovich OV, Lyulina EB, Pleteneva TV, Maksimova TV, Syroeshkin AV, Uspenskaya EV, et al. Reaction of an antioxidant (sodium sulfite) with 3-hydroxy-6-methyl-2-ethylpyridinium salts. Pharm Chem J 2015;48:842-4.

12. Experiment 3-1 Formulation Design and Preparation of Vitamin C Injections, Vitamin C; 2012. Available from: https://wenku.baidu.com/view/60867cc7a1c7aa00b42acb04. html?re=view. [Last accessed on 24 Apr 2019]

13. Pharmaceutical Medicine Technology. Available from: https://www.meddr.ru/posobie_dlya/aptechnaya_tehnologiya_lek arstv/8365. html (in Russian). [Last accessed on 05 May 2019]

14. Vitamin $C$ injection and its preparation method. Available from: https://patents.google.com/patent/CN104146952A/en. [Last accessed on 05 May 2019]

15. Mylan Institutional LLC. Ascorbic acid-Injection, USP. For intravenous, intramuscular or subcutaneous use. Available from: https://dailymed.nlm.nih.gov/dailymed/fda/fdaDrugXsl.cfm?setid $=\mathrm{d} 052$.

16. Sultana Y. Pharmaceutical microbiology and biotechnology: sterilization Methods and Principles New Delhi: Jamia Hamdard; 2007.

17. Ramirez Cahero HF, Valdivia Lopez MA. Effect of gamma radiation on sugars and vitamin C: Radiolytic pathways. Food Chem 2018;245:1131-40.

18. Silva CB, Araujo TD, Vasconcelos RL, Paula CB, Nogueira AP, Lira $\mathrm{AB}$, et al. Gamma radiation as a method for sterilization of all-in-one admixtures bags for clinical use: a study of stability. Int J Pharm Pharm Sci 2015;7:129-35.

19. Alberty RA, Sibley RJ, Daniels F. Physical chemistry. New York: Wiley; 1992.

20. Goncharuk VV, Syroeshkin AV, Zlatskiy IA, Uspenskay EV, Orekhov $\mathrm{AV}$, et al. Quasichemical description of the cell death kinetics of cellular biosensor spirostomum ambigua for testing the biological activity of aqueous solutions. J Water Chem Tech 2017;39:97-102.

21. Goncharuk VV, Pleteneva TV, Grebennikova TV, Syroeshkin AV, Uspenskaya EV. Determination of biological activity of water having a different isotope ratio of protium and deuterium. J Water Chem-Tech 2018;40:27-34.

22. Goncharuk VV, Pleteneva TV, Uspenskaya EV, Syroeshkin AV. Controlled chaos: heterogeneous catalysis. J Water Chem-Tech 2017;39:325-30.

23. Wardhani DH, Cahyono H, Aaryanti N. Performance of glucomannan-alginate combination as a $\mathrm{pH}$-sensitive excipient of vitamin C encapsulation using gelation method. Int J Appl Pharm 2019;11:185-92.

24. Klu MW, Addy BS, Oppong EE, Sakyi ES, Mintah DN. Effect of storage conditions on the stability of ascorbic acid in some formulations. Int J Appl Pharm 2016;8:26-31.

25. Hoffer LJ, Robitaille L, Zakarian R, Melnychuk D, Kavan P. Highdose intravenous vitamin $\mathrm{c}$ combined with cytotoxic chemotherapy in patients with advanced cancer: a phase I-II clinical trial. PLoS One 2015;10. Doi:10.1371/ journal.pone.0120228e0120228 